San Jose State University

SJSU ScholarWorks

Faculty Publications

Social Work

January 2000

\title{
Alcohol, tobacco, and pharmaceutical industry funding: Considerations for organizations serving lesbian, gay, bisexual and transgender communities
}

Laurie A. Drabble

San Jose State University, laurie.drabble@sjsu.edu

Follow this and additional works at: https://scholarworks.sjsu.edu/social_work_pub

Part of the Lesbian, Gay, Bisexual, and Transgender Studies Commons, Social Work Commons, Substance Abuse and Addiction Commons, and the Women's Studies Commons

\section{Recommended Citation}

Laurie A. Drabble. "Alcohol, tobacco, and pharmaceutical industry funding: Considerations for organizations serving lesbian, gay, bisexual and transgender communities" Journal of Lesbian and Gay Social Services (2000): 1-26. https://doi.org/10.1300/J041v11n01_01

This Article is brought to you for free and open access by the Social Work at SJSU ScholarWorks. It has been accepted for inclusion in Faculty Publications by an authorized administrator of SJSU ScholarWorks. For more information, please contact scholarworks@sjsu.edu. 
The manuscript following this page is an Author's Accepted Manuscript of an article published in the Journal of Lesbian and Gay Social Services, 11 (1), 1-26.

[copyright Taylor \& Francis], available online at: http://www.tandfonline.com/ [DOI: 10.1300/J041v11n01_01].

The appropriate citation for this manuscript is:

Drabble, L. (2000). Alcohol tobacco and pharmaceutical industry funding: Considerations for organizations serving lesbian, gay, bisexual and transgender communities. Journal of Lesbian and Gay Social Services, 11 (1), 1-26. 


\title{
Title, Abstract and Key Words
}

\section{TITLE:}

Alcohol, Tobacco and Pharmaceutical Industry Funding: Considerations for Organizations Serving Lesbian, Gay, Bisexual and Transgender Communities

\begin{abstract}
Emerging research suggests that alcohol, tobacco and drug-related problems may be higher in lesbian and gay communities than that of the population as a whole. At the same time, alcohol, tobacco and pharmaceutical industries have increased marketing strategies that are targeted specifically to lesbian and gay communities. Lesbian, Gay, Bisexual and Transgender (LGBT) and HIV/AIDS organizations, often marginalized and under-funded, have frequently faced significant challenges in funding programs and special events. These organizations are often the very same groups needed to promote and support effective substance abuse counter-measures in LGBT communities. Increasingly, LGBT and HIV/AIDS organizations are struggling with the dilemma of developing funding policies that are congruent with their missions. Agency leaders, community members, and substance abuse prevention advocates all have a stake in identifying reasonable guidelines for sponsorship of special events as well as contributions to nonprofit organizations. This paper discusses these issues and provides examples of guidelines that may be adopted or adapted by nonprofit and community based organizations that serve the LGBT community.
\end{abstract}

Keywords: Lesbian and gay, nonprofit management, alcohol policy, tobacco policy, pharmaceutical marketing, environmental prevention, advertising, target marketing, sponsorship, fundraising.

Acknowledgement: Research related to this paper was supported, in part, by Progressive Research for Training and Action, Oakland, California. 


\section{Alcohol, Tobacco and Pharmaceutical Industry Funding: Considerations for Organizations Serving Lesbian, Gay, Bisexual and Transgender Communities}

\section{Overview}

Promotions by the alcohol and tobacco industry include sponsorship of special events and cultural holidays, contributions to nonprofit organizations, and advertising in culturally and population specific publications (Hacker, Collins, \& Jacobson, 1987; Kilbourne, 1991; Maxwell

\& Jacobson, 1989). Lesbian, gay, bisexual and transgender (LGBT) communities and HIV/AIDS organizations have increasingly been targeted for specialized marketing. At the same time that these promotional activities are increasing, emerging research suggests that alcohol and tobacco use in LGBT communities may be higher than that of the population as a whole. While there is currently heated debate about the prevalence of alcohol, tobacco and other drug use among lesbian, gay, bisexual and transgender populations because of methodological limitations in some studies, there is concern that such behaviors are a significant problem that warrants attention, both in terms of treatment and prevention.

The purpose of alcohol and tobacco advertising (as with all advertising) is to increase consumption, recruit new users, and promote specific brand use (Kilbourne, 1991). The first two goals of advertising have negative implications for LGBT communities, particularly in terms of health problems. For example, in relation to HIV/AIDS, which continues to impact gay males disproportionately, studies show that both alcohol and tobacco compromise the immune system of HIV positive individuals (DHHS, 1994; Nieman, Fleming, \& Coker, 1993). Alcohol use may be associated with unsafe sex (Meyer \& Dean, 1995), although methodological problems in studies to date make it difficult to clearly establish this relationship (Donovan \& NcEwan, 1995). 
Many public health advocates are concerned about the impact of accepting alcohol and tobacco industry funding on the policies and practices of public benefit organizations and fear that accepting tobacco and alcohol funding may affect policy and programmatic choices. A national survey of nonprofit organizations found that agencies accepting alcohol funding were less likely to endorse alcohol policy measures (e.g. restrictions on availability to minors, governmental intervention to reform alcohol advertising, policies addressing alcohol availability within the organization, etc.) (Mosher \& Frank, 1994). Three of the organizations demonstrating strong advocacy for alcohol policy initiatives took these positions only after electing to refuse alcohol industry funding. Another study suggested that magazines that carry tobacco ads are 38 percent less likely to address smoking risks than those without tobacco ads and coverage of cigarette risks tends to decrease as tobacco revenue increases (Warner, Goldenhar, \& McLaughlin, 1992). A San Diego community assessment found high rates of alcohol ads and significant coverage of general HIV/AIDS issues in local lesbian and gay publications, but little coverage of alcohol and other drug problems and no mention of the possible link between HIV and alcohol use (Kelly, 1995).

Advertising and promotion by pharmaceutical manufacturers, in many cases, may serve to increase awareness of health problems and inform health care providers about the most effective medications for preventing and curing illness (Mossinghoff, 1992). At the same time, many health advocates are also concerned about balancing recognition of benefits of pharmaceutical company promotion with consideration of potential harm for consumers in both the U.S and abroad (Silverman, Lydecker, \& Lee, 1992). A number of health agencies and "watchdog” organizations including Project Inform (an HIV/AIDS consumer advocacy organization) and the National Women's Health Network have adopted policies to limit or refuse 
industry sponsorship to avoid potential conflict of interest. The Gay and Lesbian Medical Association (GLMA) appears to be the first national LGBT organization to adopt a comprehensive written policy establishing guidelines for accepting support from the pharmaceutical industry and precluding acceptance of direct funding from tobacco and alcohol industries (GLMA, 1998a; GLMA, 1998b).

The last two decades have also brought advances in understanding the dynamics of alcohol, tobacco, and other drug- related problems among specific populations, including LGBT communities. Much of the literature on alcohol and lesbian/gay communities is focused on treatment considerations (Anderson \& Henderson, 1985; Cabaj, 1996; Diamond \& Wilsnack, 1978; Finnegan \& McNally, 1987; Glaus, 1988; Hall, 1993; Herbert, Hunt, \& Dell, 1994; Icard \& Traunstein, 1987; Kus, 1990; Lewis \& Jordon, 1989; Paul, Stall, \& Bloomfield, 1991; Underhill \& Ostermann, 1991; Zigrang, 1985). The prevention literature is dominated by a focus on individual risk factors of gay/lesbian youth (Rotheram-Borus, Rosario, Van Rossem, Reid, \& Gillis, 1995; Savin-Wiliams, 1994; Shifrin \& Solis, 1992) or on preventing alcohol/drug related HIV/AIDS transmission among gay and bisexual men (Icard, Schilling, El-Bassel, \& Young, 1992; McKirnan, Stokes, Doll, \& Burzette, 1995; Rotheram-Borus et al., 1994; Stall, McKusick, Wiley, \& Coates, 1986).

A small but growing body of work integrates consideration of environmental factors in lesbian and gay alcohol, tobacco and drug-related problems (Kelly, 1995; Mongeon \& Ziebold, 1982; NALGAP, 1994; Stall \& Wiley, 1988). There is also a growing literature related to policy considerations and advancing public health strategies to address the intersecting concerns of substance use and HIV/AIDS (Bux, 1996; DHHS, 1997; Gorman, Morgan, \& Lambert, 1995; McKirnan, Ostrow, \& Hope, 1996; Paul, Barrett, Crosby, \& Stall, 1996; Paul et al., 1991; Perry, 
Solomon, Winette, \& Kelly, 1994; Sullivan, Nakashima, Purcell, \& Ward, 1998). For example, recommended action steps from a convening on HIV prevention and alcohol and other drug use prevention among men who have sex with men (MSM) included development of tools to evaluate programs using social and environmental change to promote individual change among MSM, closer collaboration between researchers and community based prevention programs, and further research on cultural and societal factors in addressing HIV and substance abuse prevention among MSM of color (DHHS, 1997). Other experts in HIV/AIDS and substance abuse prevention call for public health solutions that address environmental issues and build on community assets. Such ideas include use of social interventions and community building for HIV prevention (Rofes, 1998) and adopting a marketing approach that integrates prevention activities into arenas that people are already willing to engage in (e.g. health clubs or social services) (McKirnan et al., 1996). Increasing availability of population specific alcohol and drug treatment programs and prevention services may also serve to reduce HIV/AIDS and other health problems (Paul et al., 1996).

In addition to literature specific to substance abuse and HIV/AIDS prevention, an emerging discussion in the LGBT literature provides a critique of the larger cultural and economic impacts of target marketing (Freitas, Kaiser, \& Hammidi, 1996; Ingebretsen, 1999; Penaloza, 1996). These analyses point to the importance of balancing perceived social validation of inclusion as a "market" and larger movement goals, issues that are particularly critical when they intersect with the health of the LGBT community.

This paper explores research on the prevalence and correlates of alcohol, tobacco and other drug-related problems in lesbian/gay communities and issues related to target marketing by alcohol, tobacco and pharmaceutical industries. Several questions are explored in the context of 
this research. Why should target marketing by alcohol, tobacco and pharmaceutical industries be of concern to LGBT organizations and HIV/AIDS agencies? What are the implications for future development of environmental prevention strategies in LGBT communities? What guidelines might be adopted by LGBT and HIV/AIDS organizations to guide policy about fundraising and sponsorship from alcohol, tobacco and pharmaceutical industries?

\section{Prevalence and correlates of alcohol and tobacco use}

Research specific to alcohol, tobacco and other drug use among lesbian, gay, bisexual, and transgender populations provide a useful foundation for consideration of possible strategies for reduction of problems associated with these behaviors. Although substantial advances in research have been made, a number of ongoing methodological issues have yet to be overcome to provide a clearer picture of alcohol patterns and problems in LGBT communities in comparison to heterosexual communities. Bux (1996) identifies a number of limitations in current research including problems with representativeness of study samples (that are generally drawn from urban areas or from individuals actively involved in various community organizations); a paucity of research focused on lesbians, bisexuals, and LGBT communities of color; and failure of most studies to identify the relationship status of respondents. Although one recent study suggests that alcoholism and drug abuse is a concern among transgenders and transsexuals in one urban city (Yep \& Pietri, 1999), there is a lack of research about alcohol, tobacco and other drug issues in this population. The research, summarized below, suggests that alcohol, tobacco, and other drug consumption rates may be higher in lesbian, gay and bisexual communities. However, even if all these rates were comparable to the general population, exploration of community-specific prevention strategies would still be warranted. 
Early studies of alcohol and drug use in the gay community, which suggested high rates of alcoholism and addiction, have been contradicted in recent years. These initial studies were based on opportunistic samples primarily accessed through gay bars (Anderson \& Henderson, 1985; Fifield, 1975; Fifield, Latham, \& Phillips, 1977; Saghir, Robins, Walbran, \& Gentry, 1970) and suggested an approximate 30 percent prevalence rate of heavy or alcoholic drinking (Fifield, 1975; Fifield et al., 1977). The high rates of drug and alcohol use found in these studies are at least in part the result of the sampling bias (Bux, 1996; Paul et al., 1991).

More recent studies (McKirnan \& Peterson, 1989a; Skinner, 1994) using a less biased sampling strategy found less dramatic differences in heavy drinking between lesbian and gay populations compared to results of similar findings for the general population. These studies did not find a higher proportion of heavy drinkers among the homosexual sample but did find significantly fewer abstainers among lesbians and gay men compared to the general population. Skinner and Otis $(1992,1994)$ found a lower rate of abstention of alcohol use (in the past month) among lesbians and gay men as compared to heterosexuals. Substance abuse among adolescent lesbian and gay youth may also be disproportionately high. Remefedi (1987) studied a sample of 29 (predominantly Caucasian) adolescent gay males and found that 83\% admitted to past or current use of illicit drugs, $14 \%$ considered themselves to be chemically dependent, $17 \%$ had undergone treatment, and 58\% met the DSM III criteria for substance abuse. Rotheram-Borus et. al (1994) also found high rates of alcohol and drug use among a sample of predominantly Hispanic and Black adolescent gay men.

Despite the fact that rates of heavy drinking did not differ across samples, the homosexual sample showed higher rates of alcohol-related problems, especially among lesbians and older gay and lesbian respondents (McKirnan \& Peterson, 1989a). A “problem” was 
measured as at least two symptoms related to loss of control or dependence over the past year. This problem definition was based on a condensed version of dependency and loss of control scales used in national studies of the general population (Clark \& Midanik, 1982). The greater overall problem rate may be related to the fact that the lesbian and gay sample evidenced less decrease in alcohol and drug use with age and greater consumption rates among female respondents than in the general population (McKirnan \& Peterson, 1989a). McKirnin and Petterson (1989a) found that in 26-34 year age group, 81.3 percent of lesbians and 66.7 percent of gay men used alcohol in the past month compared to rates of 55.2 percent for women and 73.7 for men in the general population. Skinner and Otis (1992) also found a 5 percent decrease in alcohol use among lesbians 35 and older with an overall rate that was still above 80 percent, while among heterosexual women in the same age group just over half were using alcohol after a 16 percent drop (Skinner \& Otis, 1992).

Several theories have been proposed to explain the etiology of drinking problems in lesbian, gay and bisexual populations, generally focusing on unique psychological processes or larger social and cultural factors that impact lesbians and gay men, though none of these postulations has strong empirical support (Bux, 1996). Internalized homophobia, stressors related to the coming out process, disinhibition during sexual activity, and external homophobia (including lack of awareness on behalf of treatment agencies) have all been cited as possible contributors to alcohol problems (EMT, 1991; Fifield et al., 1977; Kus, 1990; Mongeon \& Ziebold, 1982; Paul et al., 1991). Hughes and Wilsnack (1997) suggest that lesbians may be disproportionately impacted by certain risk factors that correlate to alcohol consumption among women in general including problems related to underemployment, job discrimination, stressors related to multiple roles and family conflict, tendencies to engage in drinking behaviors that 
parallel significant others, and reduction of factors thought to protect heterosexual women (e.g. traditional roles and childrearing). A number of authors have suggested that bar culture and the centrality of bars as a "safe" place to congregate has contributed to alcohol-related problems in lesbian/gay communities (Fifield, 1975; Israelstam \& Lambert, 1984; McKirnan \& Peterson, 1988; Mongeon \& Ziebold, 1982; Weathers, 1980). The first survey research designed to explore the importance of bars and stress associated with being gay in a homophobic culture (McKirnan \& Peterson, 1988; McKirnan \& Peterson, 1989b) found that subjects reporting greater experiences of discrimination were more likely to use bars as a social resource. Those reporting greater "negative affectivity” (i.e., alienation, depression, low self-esteem) were more likely to use alcohol as a tool for coping with stress as well as rely on bars as a social resource.

Overall consumption of other drugs may be higher in lesbian and gay populations. McKirnan and Peterson (1989a) found higher rates of past-year marijuana use (56\%) and cocaine use (23\%) in the homosexual sample compared to rates of past-year use of marijuana (20\%) or cocaine (8.5\%) in the general population. They also found that while the general population's use of marijuana and cocaine declined substantially as the population aged, "a high proportion of older homosexuals reported lifetime use of these drugs” (p. 550). Non-medical use of psychotherapeutics may also be higher among lesbians and gay men. For example, Skinner (1994) found non-medical use of stimulants in 4.6 percent of gay men and 1.1 percent of lesbians and non-medical use of tranquilizers in 1.9 percent of gay men and 1.6 percent of lesbians. By contrast, the National Household Survey on Drug Abuse in 1995 found non-medical stimulant use among .4 percent of men and .3 percent of women as well as tranquilizer use of .5 percent among men and .3 percent among women (SAMHSA, 1995). 
Prevalence of tobacco use appears to be substantially higher among lesbians and gay men in comparison to the population as a whole. For example, Skinner (1994) found that 35.4 percent of gay men and 38.1 percent of lesbians smoked cigarettes in the past month compared to 27.1 percent of men and 22 percent of women in a general sample from the 1990 National Household Survey on Drug Abuse. A national lesbian health care survey found that 30 percent of the sample smoked cigarettes daily, another 11 percent were occasional smokers, and AfricanAmerican lesbians had higher rates of regular tobacco use (49 percent) (Bradford, Ryan, \& Rothblum, 1994).

Overall, studies appear to suggest that alcohol and other drug use is correlated with risky sexual behavior among gay and bisexual men and youth (Gorman, 1996; Gorman et al., 1995; Hays et al., 1997; Meyer \& Dean, 1995; Paul, Stall, Crosby, \& Barrett, 1994; Shoptaw, Reback, Frosch, \& Rawson, 1998; Sullivan et al., 1998; Sullivan, 1996). For example, a longitudinal study following a sample of 337 gay men who were HIV negative at baseline, found that seroconverters (men converting to HIV positive status) were more likely to report heavy use of alcohol and use of other drugs than non-converters (Chesney, Barrett, \& Stall, 1998). This risk does not appear to be exclusive to gay men. A mail survey of 844 adults (76 percent heterosexual) found a relationship between frequency of alcohol and drug use and participation in risky sexual behavior (Leigh, 1990).

In a review of the literature on substance use, HIV and gay men, Ostrow (1996) found strong evidence for a direct association between substance use and risk of HIV infection in case control studies examining behavioral associated with seroconversion among groups of men. This strong association does not imply that substance use is a direct "cause” of risky sexual behavior. Ostrow points out that studies examining episodes of drug use and sexual activity in 
individuals (event analysis, which is best suited to determining if there is a causal relationship between these behaviors) suggest indirect causal factors such as expectations about the effects of alcohol or other drug use on sexual behavior. For example, a study of alcohol use prior to sexual activity was related to unprotected anal intercourse among bar-going gay men found that occasions of heavy alcohol use and frequent unprotected anal intercourse tended to occur among the same individuals, but that a causal relationship was not established (Perry et al., 1994). Ostro (1996, p. 3) points out that "with the epidemiological evidence strongly pointing to the role of drugs and the combination of drugs and risk sex in promulgating new waves of HIV seroconversion among men who have sex with men, the stakes seem too high to fail to invest resources in prevention.”

\section{Alcohol and Tobacco Advertising and Promotion}

Marketing of alcoholic beverages and tobacco products is often targeted to specific communities based on geography, age, culture, gender and lifestyle (Holder, 1992; Krupka \& Vener, 1992). In recent years, there has been an increase in the development of new alcohol and tobacco promotions targeting specific populations including women (Kilbourne, 1991; Krupka \& Vener, 1992), African Americans (Hacker et al., 1987; Pollay, Lee, \& Carter-Whitney, 1992) and Hispanics (Maxwell \& Jacobson, 1989). Promotions by the alcohol and tobacco industries include sponsorship of special events and cultural holidays, contributions to nonprofit organizations, and advertising in culturally and population specific publications (Hacker et al., 1987; Kilbourne, 1991; Maxwell \& Jacobson, 1989). A number of prevention advocates question whether these promotions are philanthropy or profit motivated. For example, one

alcohol beverage company, Coors, invested significant funds into both African American and 
Hispanic communities to counter a poor reputation (and a boycott) based on discriminatory company practices related to labor and minorities (Hacker et al., 1987; Marin Institute, 1992;

Maxwell \& Jacobson, 1989). In many cases, the level of benefits to communities was linked to the level of consumption (Maxwell \& Jacobson, 1989) and documents from managers of Coors’ Community Relations department specifically note the increase in product sales associated with marketing in minority communities (Hacker et al., 1987, p.35).

Similar marketing strategies are being used to target lesbian and gay communities. The alcohol and tobacco industry targets lesbian and gay communities through four primary methods: sponsorship, fundraising, advertising and promotions (Rahn, 1994).

\section{Sponsorship}

Corporate sponsorship of cultural events has become common and provides an opportunity to promote a product in an environment relatively free from interference by other commercial messages, helps to increase consumer goodwill, and facilitates association of the product with the positive image of the event (Stewart \& Rice, 1995). The alcohol and tobacco industries target lesbian and gay communities using sponsorship strategies that parallel those used to target different race and ethnic groups. As a case in point, Coors Brewing Company, which has been boycotted by lesbian and gay communities for anti-gay practices and funding of homophobic right-wing organizations, has launched a public relations campaign centered on offering high visibility contributions to lesbian and gay public events. Coors has offered support to the Los Angeles Christopher Street West Pride Festival, OutFest Lesbian and Gay Film Festival, the San Jose Pride Parade, and the San Francisco’s Lesbian and Gay Community Center Project (Mirken, 1997). Coors continues to improve its corporate image and expand sales by advertising in gay and lesbian publications around the country while the Coors family fund 
donates to organizations like the Free Congress Foundation, one of the nations' largest distributors of extremely homophobic literature and a strong advocate for anti-gay policies (e.g. reintroducing and enforcing anti-sodomy laws) (Bellant, 1991).

\section{Fundraising}

In addition to sponsoring specific events, the alcohol industry provides direct funding to national and local non-profit organizations. For example, alcohol companies "buy good will” by donating to the United Negro College Fund, the National Hispanic Scholarship Fund, the National Urban League, the U.S. Hispanic Chamber of Commerce and the Office for the Advancement of Public Black Colleges (Marin Institute, 1992). Similar donations are made to lesbian and gay organizations.

Alcohol industries also purchase visibility and divert attention from harmful effects of alcohol in gay communities through donation of proceeds to HIV/AIDS organizations (Rahn, 1994). For example, Absolut Vodka launched a national campaign inviting artists to create images featuring the Absolut bottle central to everyday activity in gay life, used the art in promotions, and donated money from sales of the artwork to AIDS organizations (Rahn, 1994). It is important to note that some studies suggest that alcohol use is associated with unsafe sex (Meyer \& Dean, 1995) and compromise of the immune system (DHHS, 1994). Thus, the alcohol industry has an investment in minimizing this association. For example, the National Beer Wholesalers Association attempted to intervene in the National Institute on Drug Abuse "Get High, Get Stupid, Get AIDS” campaign and called it an “indictment of beer” (Rahn, 1994). Mosher and Frank (1994) surveyed 62 national nonprofit organizations to assess their support for nine alcohol policy measures and to identify whether or not they had an organizational policy related to accepting or rejecting alcohol funding. The study found strong 
overall support for alcohol policy measures, particularly among medical associations, alcohol and drug agencies and faith communities. Two-thirds of the sample reported the existence of a policy or practice opposing the acceptance of alcohol industry funding. The presence of organizational policies and practices related to acceptance or rejection of alcohol funding was correlated with support of broader alcohol policy measures. Organizations accepting alcohol funding were less likely to endorse policy measures. Indeed, three of the organizations demonstrating strong advocacy for alcohol policy initiatives (Mothers Against Drunk Driving, Students Against Drunk Driving, and National Council on Alcohol and Drug Dependencies) took these positions only after electing to refuse alcohol industry funding. Though alcohol problems are a significant health concern for organizations representing diverse populations, the rate of support for alcohol policy measures was low in this category apparently (based on comments during interviews) because these organizations are engaged in addressing issues of greater immediate concern to their constituents and have not yet considered alcohol policy issues. Lesbian and gay communities may have low rates of support for alcohol policy initiatives for similar reasons as other organizations representing diverse populations, but surveys specific to lesbian/gay organizations have yet to be conducted.

\section{Advertising}

It is difficult to establish a direct relationship between alcohol and tobacco advertising and increased consumption. A recent survey of literature concludes that alcohol advertising does appear to stimulate greater consumption, but that advertising is likely to be a contributing factor rather than a major determinant (Atkin, 1995). For example, in a study analyzing alcohol advertising in 75 cities, Saffer (1997) found a positive relationship between alcohol advertising and alcohol-related problems. Overcoming limitations in prior studies that tended to use national 
data and failed to capture the impact of “pulsing” (where the industry saturates local markets with spurts of advertising), this study showed that decreasing alcohol advertising reduces highway fatalities (Saffer, 1997). Studies also suggest that there may be a relationship between cigarette advertising and smoking among youth (Pierce \& Gilpin, 1995; Schooler, Feighery, \& Flora, 1996). For example, a study related to tobacco advertising found that Camel cigarette’s share of the under 18 market increased from .5 percent to 32.8 percent after introduction of the Joe Camel cartoon advertisement campaign (DiFranze et al., 1991). In addition, industry advertising may also impact the public by influencing the content of publications and programs. For example, research suggests that magazines that carry tobacco ads are 38 percent less likely to address smoking risks than those without tobacco ads and coverage of cigarette risks tends to decrease as tobacco revenue increases (Warner et al., 1992).

Advertising in gay publications is increasing with the top categories of advertisers including pharmaceutical companies, travel, fashion and alcohol (Wilke, 1996). Advertising, as with other mainstream publications, may influence content of gay and lesbian publications. A San Diego community assessment found high rates of alcohol ads and coverage of general HIV/AIDS issues in local lesbian and gay publications but little coverage of alcohol and other drug problems and no mention of the link between HIV and alcohol (Kelly, 1995). Gay and lesbian bars are also an important source of revenue for publications and there is often a close relationship, sometimes common ownership, between bars and gay/lesbian publishers (Kelly, 1995). 


\section{Promotions}

Price specials, alcohol-centered community based events and heavy drinking events (beer-busts) are traditional in gay bars and often encourage high-risk drinking (Rahn, 1994). An assessment of alcohol environments and problems in lesbian and gay communities in San Diego found that three-quarters of lesbian and gay organizations reported that alcohol was served at most of their events and one third reported alcohol and drug related problems at these events (Kelly, 1995). The assessment also found that bars frequently promoted events that encouraged over consumption (including "keggers” and two-for-one specials) and that bar owners had a low interest in responsible hospitality training (Kelly, 1995). The goals of responsible beverage service programs are to prevent intoxication among patrons and guests of alcohol servers, prevent service to underage persons, prevent intoxicated individuals from driving, and help promote other prevention strategies (Mosher, 1991).

\section{Pharmaceutical Industry Advertising and Promotions}

Although most strategies used by pharmaceutical manufacturers to expand product demand are ethical, some tactics have raised concerns over the years including use of video news releases, “pseudo-scientific” sessions where promotional activities are framed as educational sessions, and intensive individualized sales and incentives to physicians (Bleidt, 1992). The potential of government restrictions in 1990 served as a stimulus for the pharmaceutical industry and medical profession to develop clear guidelines in a number of areas including commercial support of medical continuing education courses and acceptance of gifts and sample products by individual practitioners (AAPA, 1993; Bleidt, 1992). However, creative marketing to health care providers, and increasingly direct marketing to consumers, continues (Basara, 1992; Bleidt, 
1992; Montagne, 1992) as will the challenge to health organizations to ensure that information targeting their communities promotes the public good and is not solely promoting industry profit. An article about selling AIDS drugs to the gay community in a marketing magazine suggests that gay community leaders and political advocacy groups in the past "have, more often than not, demonized pharmaceutical companies, the FDA, and other 'establishment' entities they view as either ineffective or actively hostile to the gay community (Kahan \& Mulryan, 1996, p. 45).” The authors describe a number of strategies that pharmaceutical industries can employ to win the "battle for market share" in a community that represents "an increasingly long-term and therefore lucrative market segment to the pharmaceutical industry (Kahan \& Mulryan, 1996, p. 43). Many of these strategies, such as communicating about the efficacy of various medications in the gay press, may prove informative to LGBT consumers. At the same time, these strategies are ultimately about market competition and commercial success for companies. In this context, organizations accepting pharmaceutical industry funds are placed in a position of balancing the interests of their constituents and consumers with those of their donor companies.

In recent years, a number of professional organizations have developed well-defined guidelines to inform the practice of individual health care providers. The pharmaceutical industry has invested substantial resources into marketing specific products in lesbian and gay communities. Although existing professional guidelines may ensure ethical relationships between individual practitioners and the pharmaceutical industry, it is also important that responsible nonprofit and health advocacy agencies develop clear organizational guidelines about practices related to accepting funding and endorsing promotions from pharmaceutical industries. Project Inform, recognizing the role of the pharmaceutical industry as both and ally 
and profit-making institution, enjoins other organizations in the preamble of their own policies to develop organizational guidelines:

Project Inform acknowledges that there is a wide range of opinion regarding policies governing donations, especially those donations coming from corporations perceived to benefit from the AIDS epidemic. Regardless of an organization’s position on this issue, it is important to be forthcoming and direct about donor relations and policies. Project Inform encourages and supports full disclosure of these policies and relations from all HIV/AIDS organizations (Project Inform, 1997).

\section{Environmental Prevention Strategies: Promoting Healthy Communities}

Over the last twenty years, a public health model that addresses the interaction between the individual (host), the agent (alcohol) and the environment (e.g. alcohol availability, alcohol pricing and alcohol promotions) has proved to have utility in understanding and preventing alcohol-related problems. Environmental prevention strategies provide an opportunity to address a wide range of factors that may serve to support or reduce alcohol, tobacco or other drug problems (Holder, 1989). For example, alcohol pricing may have an impact on alcohol-related problems including motor vehicle fatality (Grossman, Chaloupka, Saffer, \& Laizuthai, 1994), density of alcohol outlets may be correlated with increased incidents of violence (Scribner, MacKinnon, \& Dwyer, 1995), and counter-advertisements may help reduce cigarette use (Blum, 1994). Responsible beverage service training at sites where alcohol is sold has also been effective in reducing alcohol-related problems (McKnight, 1993). As a result, many government organizations, prevention advocates, and community groups have mobilized to

institute policy changes as a strategy for reducing alcohol and tobacco related problems. 
- Given the prevalence of alcohol, tobacco and other drug related problems in lesbian and gay communities combined with increased targeted marketing by the alcohol, tobacco and pharmaceutical industries, it would seem that environmental prevention strategies could be a valuable resource for LGBT communities. In general, it is important that such strategies be appropriate to lesbian and gay communities, recognize many subcultures in lesbian/gay communities (including subcultures based on race, ethnicity, and age), be led by community members, and focus on community assets and strengthening resiliency factors (Kelly, 1995). Many environmental prevention strategies center on viewing community as both a collection of people living in physical proximity (or a catchment area) and as a dynamic social and economic network for exchange (Holder, 1992). Environmental prevention strategies in lesbian and gay communities must consider the fact that, except in a limited number of urban areas, communities are not organized geographically. In addition, traditional environmental approaches that generally 1) target bars by reducing the number of bars (or prevent opening of new ones) to reduce availability or 2) improve responsible beverage service in bars and during community events must be adapted to recognize the role of bars and festivals as community institutions (Kelly, 1995).

Environmental prevention strategies that have been used to counter target marketing in different communities may offer models that could be adapted in LGBT communities. These include strategies centered on cultural events and institutions (rather then geographic communities). A number of cities and community-based organizations have developed policies related to refusing or limiting alcohol sponsorship. For example, in California, Santa Ana sponsored a successful alcohol-free Cinco de Mayo (Cal Council, 1993), the city of Irvine passed resolutions to prohibit accepting alcohol or tobacco sponsorship or promotion at youth-oriented 
or sports events at City facilities (Injury Prevention, 1991), and the Gathering of Nations (the largest celebration of Native American culture in North America) switched from Coors sponsorship to Borden Inc. that sells milk products (Marin Institute, 1992).

\section{Implications for Environmental Prevention Strategies in Lesbian, Gay, Bisexual and Transgender Communities}

There are a number of environmental prevention strategies that might be adopted in LBGT communities. (Baker, 1994; Drabble \& Soliz, 1996; Mongeon \& Ziebold, 1982;

NALGAP, 1994). These possible strategies have implications for LGBT nonprofit organizations, prevention advocates seeking to build alliances with LGBT communities, and public and private funding sources.

Nonprofit organizations in LGBT communities should develop written policy statements to guide fundraising efforts, including guidelines about donations and promotions from the alcohol, tobacco and pharmaceutical industries. Written guidelines are useful for communicating organizational values, ensuring congruence of an agency funding strategy with its overall mission, and institutionalizing guidelines for board and staff decision-making. For example, the Gay and Lesbian Medical Association has developed a comprehensive corporate sponsorship policy that includes language specifying that:

“The Gay and Lesbian Medical Association will not accept direct funding from alcohol or tobacco manufacturers or distributors. GLMA will not sponsor, co-sponsor, or be a beneficiary of any event that accepts primary or sole sponsorship (more than 50\% of event expenses) from alcohol or tobacco manufacturers or distributors (GLMA, 1998a).” 
Responsible beverage service and responsible hospitality practices may also be adopted at events and in bars where alcohol is served including promotion of and access to non-alcoholic beverages, food and safe ride programs. In addition, information might be provided about potential risks of sex under the influence of alcohol. The Ventura County Gay and Lesbian Center has adopted alcohol and drug policies, including special event guidelines stipulating that:

The alcohol industry shall support not more than 30 percent of the event’s sponsorship funding. Alcohol advertising shall be limited to alcohol sales booths. In relation to offsite events:

- All alcoholic beverage servers have to be trained in "responsible beverage service". All servers shall be trained to identify and handle intoxicated guests. All volunteers need to be trained to identify counterfeit IDs. A limit of two alcohol drinks may be served to any one person at any one time. Alcoholic beverages will be served in clear glasses or glasses that are distinctly different than those used for the non-alcoholic beverages in order to provide monitoring control. All servers of alcohol beverages are to be trained to pour 1-1/2 ox. serving of 80 proof alcohol, 12-oz. serving of beer and $5 \mathrm{oz}$. servings of wine.

- Everyone under 30 years of age will have ID checked.

- For large events such as dances, festival and fundraisers, persons 21 and older must wear non-transferable wristbands.

- Support for designated drivers will be offered. Special wrist bands for designated drivers will be distributed and free non-alcoholic beverages will be available for designated drivers. 
- Sales of alcohol will be stopped 1 hour before the event closes.

- No one will be permitted to bring alcohol into an event.

- All volunteers working at events should refrain from using alcohol.

- All rules and information to support responsible beverage service should be posted

Community groups electing to accept alcohol or pharmaceutical industry funding should put limits on the nature of promotional activity and corporate visibility allowed at events in sponsorship agreements. For example, the Gay and Lesbian Medical Association policies state that, "there shall be no distributing or displaying of fliers, posters, signs, banners, dispensers, programs, activities or apparel bearing the name or logo of an alcohol or tobacco product manufacturer at any GLMA sponsored event or in any GLMA communication medium (GLMA, 1998a).”

LGBT and HIV/AIDS organizations, particularly organizations addressing health issues that are most likely to be of interest to the pharmaceutical industries, should develop policies to insure independence of programming and access to unbiased information to the constituents. Project Inform donations guidelines for sponsored educational events reflect these considerations:

Given the important role these events can play in developing treatment strategy, it is essential that Project Inform staff and volunteers guarantee that:

- The content of presentations is based on scientifically accurate, up-to-date information, presented in a balanced, objective manner and not modified or influenced by corporate or other donors. 
- That there be full disclosure of any direct corporate support of the meeting on any related flyer or advertisement, and by announcement at the event.

- That there be disclosure of guest presenter's financial relationship to any company that produces any drugs or therapies discussed at the meeting by the presenter (Project Inform, 1997).

Institutions in LGBT communities, including HIV/AIDS organizations, social organizations, religious institutions and other nonprofit agencies can explore opportunities to integrate prevention strategies, including environmental prevention strategies, into their work. Alcohol and tobacco free activities, especially for youth, should be available and lesbian/gay organizations could better use special events to model smoke free and alcohol safe/alcohol free norms. Funded technical assistance and training could be provided to LGBT organizations to increase understanding of and capacity to implement prevention strategies.

LGBT media can play an important role in prevention of alcohol, tobacco and other drug problems. Counter advertising that serves to expose marketing strategies and myths promoted by the alcohol and tobacco industries should be developed and funded for LGBT publications. LGBT publications should develop editorial policies related to acceptance/refusal of alcohol advertising and commitment to active coverage of alcohol-related community issues. In addition, publications should develop a written statement/policy declaring independence from outside influences (including alcohol and pharmaceutical industries) in pursuit of their mission. Such policies could require signed conflict of interest statements from staff and board that include a commitment to abstain from voting on matters in which they may have a vested interest. 
Local cities or counties also have a role in advancing prevention efforts in LGBT communities. Public agencies and private foundations should fund specific LGBT alcohol and other drug prevention programs or, at minimum, include lesbian and gay organizations in existing community-based prevention strategies. In addition, technical assistance and training for youth-oriented and community-based environmental prevention programs could be used to enhance their capacity to be more inclusive of and responsive to LGBT populations.

Finally, additional research needs to be conducted to guide community planning and policy-making. Research specific to alcohol, tobacco and other drug problems in, and strategies that work for, LGBT communities should be funded, particularly with lesbians and LGBT communities of color. In addition, epidemiological research and prevention research should begin to include demographic questions about sexual identity and sexual behavior that would provide valuable data about LGBT communities in the future.

\section{Conclusion}

Prevention and reduction of alcohol, tobacco and other drug problems is important to the health of LGBT individuals and communities. Unbiased information about pharmaceutical products and education about their use are also important to the health of diverse communities, particularly communities impacted by HIV/AIDS. Environmental factors should be considered as a critical component of promoting individual and community health, including promotion of products that have a direct health impact. Target marketing to LGBT communities by alcohol, tobacco and pharmaceutical industries represent a growing challenge to community based organizations, particularly given a context where these organizations are frequently underfunded and disregarded by other potential funding sources. Consequently, organizations 
committed to advancing the health of diverse LGBT communities should consider adopting policies related to corporate funding and promotions. These organizational policies can serve to 1) affirm the high value the organization places on the lives and health of LGBT people, 2) ensure that the organization is independent from outside influences in the pursuit of their mission, and 3) avoid potential or perceived conflict of interest. 


\section{REFERENCES}

AAPA. (1993). PA's and the pharmaceutical industry. Journal of the American Academy of Physician Assistants, 6, 291-294.

Anderson, S. C., \& Henderson, D. C. (1985). Working with lesbian alcoholics. Social Work, 30, 315-525.

Atkin, C. K. (1995). Survey and experimental research on effects of alcohol advertising. In NIAAA (Ed.), The effects of the mass media on the use and abuse of alcohol (Research Monograph 28, pp. 39-68). Rockville, MD: US Department of Health and Human Services, National Institute on Alcohol Abuse and Alcoholism.

Baker, J. (1994). Why and how you should form a gay and lesbian ATOD prevention program in your community. Prevention Pipeline, 7(6), 21-23.

Basara, L. R. (1992). Direct-to-consumer advertising: Today's outlook and tomorrow's outlook. Journal of Drug Issues, 22(2), 195-203.

Bellant, R. (1991). The Coors connection. Boston, MA: South End Press.

Bleidt, B. (1992). Recent issues and concerns about pharmaceutical industry promotional efforts. Journal of Drug Issues, 22(2), 407-415.

Blum, A. (1994). Paid counter-advertising: Proven strategy to combat tobacco use and promotion. Journal of Preventive Medicine, 10(3), 8-10.

Bradford, J., Ryan, C., \& Rothblum, E. D. (1994). National lesbian health care survey: Implications for mental health care. Journal of Consulting and Clinical Psychology, 62(2), 228242. 
Bux, D. (1996). The epidemiology of problem drinking in gay men and lesbians: A critical review. Clinical Psychology Review, 16(4), 227-298.

Cabaj, R. P. (1996). Substance abuse in gay men, lesbians and bisexuals. In R. P. Cabaj \& R. S. Stein (Eds.), Textbook of homosexuality and mental health (pp. 783-799). Washington, DC: American Psychiatric Press.

Cal Council. (1993). A first for Santa Ana Celebrating Cinco de Mayo Alcohol-Free. $\underline{\text { Cal }}$ Council Report, VII, 4.

Chesney, M. A., Barrett, D. C., \& Stall, R. (1998). Histories of substance use and risk behaviors: Precursors to HIV seroconversion in homosexual men. American Journal of Public Health, 88(1), 113-116.

Clark, W. B., \& Midanik, L. (1982). Alcohol use and alcohol problems among U.S. adults: Results of the 1970 national survey. In Alcohol and health: Alcohol consumption and related problems (Alcohol and Health Monograph No. 1, ADM Publication Number 82-1190, pp. 3-52). Washington, DC: U.S. Government Printing Office.

Department of Health and Human Services (DHHS. (1994). Eighth special report to the U.S. Congress on alcohol and health (NIH Publication No. 94-3699). Rockville, MD: National Institute on Alcohol Abuse and Alcoholism.

Department of Health and Human Services (DHHS). (1997, September). The Northwest Regional workshop: HIV prevention approaches for alcohol and drug use among men who have sex with men . U.S. Department of Health and Human Services, Public Health Service, Centers for Disease Control and Prevention.

Diamond, D. L., \& Wilsnack, S. C. (1978). Alcohol abuse among lesbians: A descriptive study. Journal of Homosexuality, 4(2), 123-142. 
DiFranze, J. R., Richards, J. W., Paulman, P. M., Wolf-Gillespie, N., Fletcher, C., Jaffee, R. D., \& Murray, D. (1991). RJR Nabisco's cartoon camel promotes camel cigarettes to children. Journal of the American Medical Association, 266(22), 3149-3153.

Donovan, C., \& NcEwan, R. (1995). A review of the literature examining the relationship between alcohol use and HIV-related sexual risk-taking in young people. Addiction, 90, 319328.

Drabble, L., \& Soliz, G. (1996, October, 3-4). Final report. Alive with pleasure: Prevention of tobacco and alcohol problems in lesbian, gay, bisexual and transgender communities., Milbrae, CA. (Available from Progressive Research and Training for Action, 440 Grand Ave, Oakland, CA 94610-2888)

Evaluation, Management and Training, Inc (EMT). (1991). Gay men, lesbians, and their alcohol and other drug use: A review of the literature. Sacramento, CA: Author.

Fifield, L. H. (1975). Alienated, isolated and drunk. Los Angeles, CA: Gay Community Services Center and Department of Health Services.

Fifield, L. H., Latham, J. D., \& Phillips, C. (1977). Alcoholism in the gay community: The price of alienation, isolation and oppression. Los Angeles, CA: Gay Community Services Center.

Finnegan, D. G., \& McNally, E. B. (1987). Dual identities: Counseling chemically dependent gay males and lesbians. Center City, MN: Hazelden.

Freitas, A., Kaiser, S., \& Hammidi, T. (1996). Communities, commodities, cultural space, and style. Journal of Homosexuality, 31(1/2), 83-107.

Glaus, K. O. (1988). Alcoholism, chemical dependency and the lesbian client. Women and therapy, 8(1/2), 131-144. 
Gay and Lesbian Medical Association (GLMA). (1998a). Gay and Lesbian Medical Association guidelines: Corporate funding and corporate sponsorship . San Francisco, CA: Author. (Available: http://www.glma.org.pcoi.html ).

Gay and Lesbian Medical Association (GLMA). (1998b). Gay physicians say "no" to alcohol and tobacco money (Available: http://www.glma.org/media/newsrelease/n.html ). San Francisco, California: Author.

Gorman, M. (1996). Speed use and HIV transmission. Focus: A Guide to AIDS Research and Counseling, 11(7), 4-6.

Gorman, M. E., Morgan, P., \& Lambert, E. Y. (1995). Qualitative research considerations and other issues in the study of methampetamine use among men who have sex with men. In E. Y. Lambert, R. S. Ashery, \& R. H. Needle (Eds.), Qualitative methods in drug abuse and HIV research (NIDA Research Monograph 157, NIH Pub. No. 95-4025, pp. 156-181). Rockville, MD: National Institute on Drug Abuse.

Grossman, M., Chaloupka, F. J., Saffer, H., \& Laizuthai, A. (1994). Effects of alcohol price policy on youth: A summary of economic research. Journal of Research on Adolescence, 4(3), 347-364.

Hacker, G., Collins, R., \& Jacobson, M. (1987). Marketing Booze to Blacks. Washington, DC: Center for Science in the Public Interest.

Hall, J. (1993). An exploration of lesbians' images of recovery from alcohol problems. In P. S. Noerager (Ed.), Lesbian Health: What are the Issues? (pp. 91-108). Washington D.C.: Taylor \& Francis.

Hays, R. B., Paul, J., Ekstrand, M., Kegeles, S. M., Stall, R., \& Coates, T. J. (1997). Actual versus perceived HIV status, sexual behaviors and predictors of unprotected sex among 
young gay and bisexual men who identify as HIV-negative, HIV-positive and untested. AIDS, 11(12), 1495-1502.

Herbert, J. T., Hunt, B., \& Dell, G. (1994). Counseling gay men and lesbians with alcohol problems. Journal of Rehabilitation, 60(2), 52-57.

Holder, H. (1989). Prevention of alcohol-related problems. Alcohol Health and Research World, 13(4), 339-342.

Holder, H. (1992). What is a community and what are implications for prevention trials for reducing alcohol problems? In H. D. Holder \& J. M. Howard (Eds.), Community Prevention Trials for Alcohol Problems: Methodological Issues (pp. 15-33). Westport, CT: Praeger Publishers.

Hughes, T. L., \& Wilsnack, S. C. (1997). Use of alcohol among lesbians: Research and clinical implications. American Journal of Orthopsychiatry, 67, 20-36.

Icard, L., \& Traunstein, D. M. (1987). Black, gay, alcoholic men: Their character and treatment. The Journal of Contemporary Social Work, 68(5), 267-272.

Icard, L. D., Schilling, R. F., El-Bassel, N., \& Young, D. (1992). Preventing AIDS among black gay men and black gay and heterosexual male intravenous drug users. Social Work, 37(5), 440-445.

Ingebretsen, E. (1999). Gone shopping: The commercialization of same-sex desire. Journal of Gay, Lesbian and Bisexual Identity, 4(2), 125-148.

Injury Prevention. (1991, Fall). Working to counteract the seduction of "industry "giveaways". Injury Prevention Network Newsletter, pp. 11.

Israelstam, S., \& Lambert, S. (1984). Gay bars. Journal of Drug Issues, 14, 637-654. 
Kahan, H., \& Mulryan, D. (1996, December). Mending fences: Selling AIDS drugs to the gay community. American Demographics, 18, 43-45.

Kelly, J. (1995). Preventing alcohol and other drug problems in the lesbian and gay community . Sacramento, CA: EMT Group, Inc.

Kilbourne, J. (1991). The spirit of the czar: Selling addictions to women. In P. Roth (Ed.), Alcohol and drugs are women's issues: A review of the issues. (Vol. 1, pp. 10-22). New York, NY: Women's Action Alliance and Scarecrow Press.

Krupka, L. R., \& Vener, A. M. (1992). Gender differences in drug (prescription, nonprescription, alcohol and tobacco) advertising: Trends and implications. Journal of Drug Issues, 22(2), 339-360.

Kus, R. (1990). Alcoholism in the gay and lesbian communities, Keys to caring: Assisting your gay and lesbian clients (pp. 66-81). Boston: Alyson Publications.

Leigh, B. C. (1990). The relationship of substance use during sex to high-risk sexual behavior. Journal of Sex Research, 27(2), 199-213.

Lewis, G. R., \& Jordon, S. M. (1989). Treatment of the gay or lesbian alcoholic. In G. W. Lawson \& A. W. Lawson (Eds.), Alcoholism \& substance abuse in special populations (pp. 165203). Rockville, MD: Aspen Publishers.

Marin Institute for the Prevention of Alcohol and Other Drug Problems. (1992, Winter). Booze makers buy into racial/ethnic communities. The Marin Institute for the Prevention of Alcohol and Other Drug Problems Newsletter. Marin, CA: Author.

Maxwell, B., \& Jacobson, M. (1989). Marketing disease to Hispanics: The selling of alcohol, tobacco, and junk foods. Washington DC: Center for Science in the Public Interest. 
McKirnan, D. J., Ostrow, D. G., \& Hope, B. (1996). Sex, drugs and escape: A psychological model of HIV-risk sexual behaviors. AIDS Care, 8(6), 655-669.

McKirnan, D. J., \& Peterson, P. L. (1988). Stress, expectancies, and vulnerability to substance use: A test of a model among homosexual men. Journal of Abnormal Psychology, 97, 461-466.

McKirnan, D. J., \& Peterson, P. L. (1989a). Alcohol and drug use among homosexual men and women: Epidemiology and population characteristics. Addiction Behaviors, 14(5), 545553.

McKirnan, D. J., \& Peterson, P. L. (1989b). Psychosocial and cultural factors in alcohol and drug abuse: An analysis of a homosexual community. Addictive Behaviors, 14, 555-563.

McKirnan, D. J., Stokes, J. P., Doll, L., \& Burzette, R. G. (1995). Bisexually active gay men: Social characteristics and sexual behavior. Journal of Sex Research, 32(1), 65-76.

McKnight, A. J. (1993). Server intervention: Accomplishments and needs. Alcohol Health and Research World, 17(1), 76-83.

Meyer, H. I., \& Dean, L. (1995). Patterns of sexual behavior and risk taking among young New York City gay men. AIDS Education \& Prevention, 7, 13-23.

Mirken, B. (1997, June 12). Coors controversy explodes up and down California: SF Community Center under fire for accepting Coors donation to capital campaign. San Francisco Bay Times, pp. 2-3, 5-6.

Mongeon, J. E., \& Ziebold, T. O. (1982). Preventing alcohol abuse in the gay community: Toward a theory and model. Journal of Homosexuality, 7(4), 89-99.

Montagne, M. (1992). Drug advertising and promotion: An introduction. Journal of Drug Issues, 22(2), 195-203. 
Mosher, J. (1991). Responsible beverage services: An implementation handbook for communities. San Rafael: Marin Institute for the Prevention of Alcohol and Other Drug Problems.

Mosher, J., \& Frank, E. (1994, November). Reaching consensus: Assessing support for national alcohol policies. Paper presented at the 122nd Annual Meeting of the American Public Health Association, Washington D.C.

Mossinghoff, G. (1992). Pharmaceutical manufacturers and self-regulation of drug advertising and promotion. The Journal of Drug Issues, 22(2), 235-243.

National Association of Lesbian and Gay Alcoholism Professionals (NALGAP). (1994). NALGAP Prevention Guidelines. (Available NALGAP, 440 Grand Ave, \# 401 Oakland, CA 94610)

Nieman, R., Fleming, J., \& Coker, R. (1993). The effect of smoking on the development of AIDS in HIV-positive individuals. AIDS, 7, 705-710.

Ostrow, D. G. (1996). Substance use, HIV, and gay men. Focus: A Guide to AIDS Research and Counseling, 11(7), 1-3.

Paul, J. P., Barrett, D. C., Crosby, G. M., \& Stall, R. D. (1996). Longitudinal changes in alcohol and drug use among men seen at a gay-specific substance abuse treatment agency. Journal of Studies on Alcohol, 57, 475-485.

Paul, J. P., Stall, R., \& Bloomfield, K. A. (1991). Gay and alcoholic: Epidemiological and clinical issues. Alcohol Health and Research World, 15(2), 151-160.

Paul, J. P., Stall, R. D., Crosby, G., \& Barrett, D. C. (1994). Correlates of sexual risktaking among gay male substance abusers. Addiction, 89(8), 971-983. 
Penaloza, L. (1996). We're here, we're queer, and we're going shopping! A critical perspective on the accommodation of gays and lesbians in the U.S. marketplace. Journal of Homosexuality, 31(1/2), 9-41.

Perry, M. J., Solomon, L. J., Winette, R. A., \& Kelly, J. A. (1994). High risk sexual behavior and alcohol consumption among bar-going gay men. AIDS, 8(9), 1321-1324.

Pollay, R. W., Lee, J. S., \& Carter-Whitney, D. (1992). Separate, but not equal: Racial segmentation in cigarette advertising. Journal of Advertising, 21(1), 45-57.

Project Inform. (1997). Project Inform Donations Guidelines. San Francisco, California: Author. (Available: Project Inform, 205 13th Street, San Francisco, California 94103)

Rahn, P. (1994). Alcohol marketing to the gay community. Prevention Pipeline, 7(6), 3031.

Remafedi, G. (1987). Adolescent homosexuality: Psychosocial and medical implications. Pediatrics, 79(3), 331-337.

Rofes, E. (1998). Context is everything: Thoughts on effective HIV prevention and gay men in the United States. Journal of Psychology and Human Sexuality, 10(3/4), 133-142.

Rotheram-Borus, M. J., Rosario, M., Meyer Bahlburg, H., Koopmen, C., Dopkins, S. C., \& Davies, M. (1994). Sexual and substance use acts of gay and bisexual male adolescents in New York City. Journal of Sex Research 31, 31(1), 47-57.

Rotheram-Borus, M. J., Rosario, M., Van Rossem, R., Reid, H., \& Gillis, R. (1995). Prevalence, course, and predictors of multiple problems behaviors among gay and bisexual male adolescents. Developmental Psychology, 31(1), 75-85.

Saffer, H. (1997). Alcohol advertising and motor vehicle fatalities. The Review of Economics and Statistics, LXXIX(3), 431-442. 
Saghir, M. T., Robins, E., Walbran, B., \& Gentry, K. (1970). Homosexuality: Psychiatric disorders and disability in the male homosexual. American Journal of Psychiatry, 126, 10791086.

Substance Abuse and Mental Health Services Administration (SAMHSA). (1995). National household survey on drug abuse: Main findings 1995. (DHHS Publication No. SMA 97-3127). Rockville, MD: Department of Health and Human Services, Substance Abuse and Mental Health Services Administration.

Savin-Wiliams, R. C. (1994). Verbal and physical abuse as stressors in the lives of lesbian, gay male, and bisexual youths: Associations with school problems, running away, substance abuse prostitution, and suicide. Journal of Consulting and Clinical Psychology, 62(2), 261-269.

Scribner, R. A., MacKinnon, D. P., \& Dwyer, J. H. (1995). The risk of assaultive violence and alcohol availability in Los Angeles County. American Journal of Public Health, 85(3), 335-340.

Shifrin, F., \& Solis, M. (1992). Chemical dependency in gay and lesbian youth. Journal of Chemical Dependency Treatment, 5(1), 67-76.

Shoptaw, S., Reback, C. J., Frosch, D. L., \& Rawson, R. A. (1998). Stimulant abuse treatment as HIV prevention. Journal of Addictive Diseases, 17(4), 19-32.

Silverman, M., Lydecker, M., \& Lee, P. R. (1992). Bad medicine: The prescription drug industry in the third world. Stanford, CA: Stanford University Press.

Skinner, W., \& Otis, M. (1992, August). Drug and alcohol use among lesbian and gay people: Findings, research design, insights, and policy issues from the Trinity Project. Paper presented at the Research Symposium on Alcohol and Other Drug Problem Prevention Among 
Lesbians and Gay Men, Los Angeles, CA. Sacramento, CA: Evaluation, Management and Training Inc.

Skinner, W. F. (1994). The prevalence and demographic predictors of illicit and licit drug use among lesbians and gay men. American Journal of Public Health, 84(8), 1307-1310.

Stall, R., McKusick, L., Wiley, J., \& Coates, T. J. (1986). Alcohol and drug use during sexual activity and compliance with safe sex guidelines for AIDS: the AIDS Behavioral Research Project. Health Education Quarterly, 13(4), 359-371.

Stall, R., \& Wiley, J. (1988). A comparison of drug and alcohol use habits of heterosexual and homosexual men. Drug and Alcohol Dependence, 22, 63-74.

Stewart, D. W., \& Rice, R. (1995). Nontraditional media and promotions in the marketing of alcoholics beverages. In S. E. Martin (Ed.), The effects of the mass media on the use and abuse of alcohol (Research Monograph 28, NIH Publication No 95-3743, pp. 209-238). Rockville, MD: National Institute on Alcohol Abuse and Alcoholism.

Sullivan, P. S., Nakashima, A. K., Purcell, D. W., \& Ward, J. W. (1998). Geographic differences in noninjection and injection substance use among HIV-Seropositive men who have sex with men: Western United States vs. other regions. Journal of Acquired Immune Deficiency Syndromes and Human Retrovirology, 19, 266-273.

Sullivan, T. R. (1996). The challenge of HIV prevention among high-risk adolescents. Health \& Social Work, 21(1), 58-65.

Underhill, B., \& Ostermann, S. (1991). The pain of invisibility: Issues for lesbians. In P. Roth (Ed.), Alcohol and drugs are women's issues: A review of the issues (Vol. 1, pp. 71-77). New York: Women's Action Alliance and Scarecrow Press. 
Warner, K. E., Goldenhar, L. M., \& McLaughlin, C. G. (1992). Cigarette advertising and magazine coverage of the hazards of smoking. New England Journal of Medicine, 326(5), 305309.

Weathers, B. (1980). Alcoholism and the lesbian community. In C. Eddy \& J. L. Fords (Eds.), Alcoholism in Women (pp. 142-149). Dubuque, IA: Kendall/Hunt.

Wilke, M. (1996, September 9). Gay press sets pace with 19.6\% ad increase. Advertising Age, 67, 57.

Yep, G. A., \& Pietri, M. (1999). In their own words: Communication and the politics of HIV education for transgenders and transsexuals in Los Angeles. In W. N. Elwood (Ed.), $\underline{\text { Power }}$ in the blood: A handbook on AIDS, politics, and communication. (pp. 199-213). Mahwah, NJ: Lawrence Earlbaum.

Zigrang, T. A. (1985). Who should be doing what about the gay alcoholic? Journal of Homosexuality, 7(4), 27-36. 